\title{
Corneille et Voltaire. CEdipe, a cura di Denis Reynaud e Laurent Thirouin
}

\section{Cristina Musio}

\section{Q OpenEdition}

1 Journals

\section{Edizione digitale}

URL: http://journals.openedition.org/studifrancesi/35448

DOI: 10.4000/studifrancesi.35448

ISSN: 2421-5856

\section{Editore}

Rosenberg \& Sellier

\section{Edizione cartacea}

Data di pubblicazione: 1 novembre 2005

Paginazione: 470

ISSN: 0039-2944

\section{Notizia bibliografica digitale}

Cristina Musio, «Corneille et Voltaire. Edipe, a cura di Denis Reynaud e Laurent Thirouin», Studi Francesi [Online], 146 (XLIX | II) | 2005, online dal 30 novembre 2015, consultato il 18 avril 2021. URL: http:// journals.openedition.org/studifrancesi/35448; DOI: https://doi.org/10.4000/studifrancesi.35448

Questo documento è stato generato automaticamente il 18 avril 2021.

\section{(c) (i) $\odot$}

Studi Francesi è distribuita con Licenza Creative Commons Attribuzione - Non commerciale - Non opere derivate 4.0 Internazionale. 


\title{
Corneille et Voltaire. CEdipe, a cura di Denis Reynaud e Laurent Thirouin
}

\author{
Cristina Musio
}

NOTIZIA

AA.VV, Corneille et Voltaire. CEdipe, a cura di Denis REYNAUD e Laurent THIROUIN, Lyon, Publications de l'Université de Saint-Étienne, 2004 (Collection «Textes et ContreTextes» $\left.n^{\circ} 4\right)$, pp. 225.

1 Il volume, introdotto e annotato da Denis REYNAUD e Laurent THIRouIN dell'Université Lyon2, riunisce una serie di testi incentrati sulle versioni del mito di Edipo di Corneille e Voltaire, con lo scopo di ricostruire quello che nell'introduzione i curatori definiscono «un moment capital de l'histoire du théâtre classique français» (p. 5). A questo scopo il libro raccoglie, oltre alla tragedia di Corneille (1659) e a quella di Voltaire (1718), l'Examen della propria pièce di Corneille (1660), la Troisième Dissertation dell'abbé d'Aubignac (1663), tre lettere di Voltaire scritte nel 1719 e le Remarques di Voltaire sull'Edipo di Corneille (tratte da Commentaires sur Corneille del 1764). L'elemento più evidente che emerge dalla lettura di tali testi è la generale convinzione degli autori dell'inadeguatezza dell'intrigo della vicenda di Edipo per un'epoca nella quale la «vraisemblance» e la «bienséance» a teatro sono fondamentali. In effetti entrambi gli scrittori cercano di adattare la tragedia di Sofocle ai gusti del tempo e giustificano le loro scelte: Corneille nell'Examen e Voltaire nella terza delle lettere raccolte in questa edizione. Nelle altre due lettere egli è impegnato a criticare aspramente le versioni di Sofocle e Corneille, ma se qui egli ancora considera il suo predecessore francese più meritevole di rispetto del tragico greco, nelle Remarques il suo giudizio sull'Edipo di Corneille diventa più severo: si tratta di una tragedia assolutamente indegna del grande drammaturgo francese. Corneille, peraltro, non riceve critiche soltanto da Voltaire: la Troisième Dissertation dell'abbé d'Aubignac è un vero e proprio pamphlet contro lo scrittore normanno, al quale viene contestato innanzitutto il fatto che egli abbia deciso di tornare a scrivere per il teatro solo per 
soldi, dopo un silenzio di sette anni. Inoltre la scelta del soggetto è stata del tutto assurda, perché non adatto ai gusti dell'epoca e soprattutto perché manca totalmente di «vraisemblance»; il delineamento del carattere dei personaggi inadeguato e la versificazione criticabile.

2 Con questa raccolta di testi, il volume vuole proporre una riflessione critica sulla ricezione del mito di Edipo in Francia in un periodo di grande splendore per il teatro. 